\title{
استخدام مونة البيرلايت في تلييس المنشات والمباني السكنية
}

\author{
الأستاذ ليلي خسانفنا، الأستاذ فاليري ليسفيك، الاكتور محمود حسني شكارنة الانة الإنة

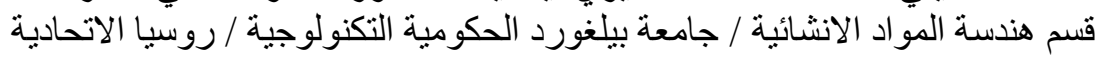 \\ husnil9_^r@yahoo.com

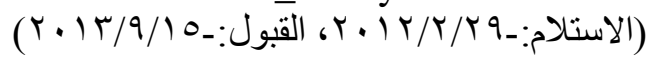

الخلاصة

إن من طبيعة المجتمع العربي التركيز في البناء على المنازل السكنية والفيلات التي نوفر الخصوصية والراحة والرفاهية، كما ان ارتفاع عدد افراد العائلة الواحدة يوجب على لتريز الكثير من الناس العيش في بيوت منفصلة او فيلات، لكن هذه المنازل والبيوت ونحن نعيش القرن الواحد والعشرون وهو قرن التقدم العلمي والتقني يجب ان ان تكون مبنية من مواد تلبي متطلبات العصر بتضمينها بكثير من المواصفات العالمية وفي هذا المجال نذكر ان من اهم هذه المواصفات هي وني

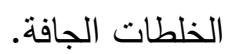

يهدف البحث الى بيان اهم ميزات الخلطات الجافة (خلطات البيرلايت) التي تستخدم في الوقت الحاضر بشكل كبير في تلييس المباني والمنشات، وتبيين اهم المواصفات والثروط التي يجب ان تلبيها هذه الخلطات ، وكذلك المضافات التي تستخدم لزيادة فعاليتها. تم التوصل من خلال نتائج التجارب العلمية ان حصلنا على خلطات جافة باستخدام البيرليت ذات مواصفات

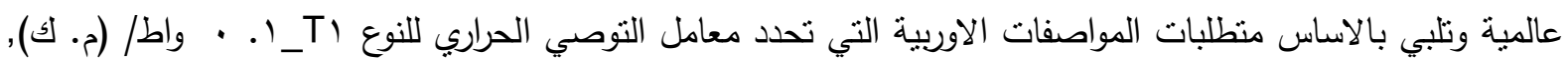

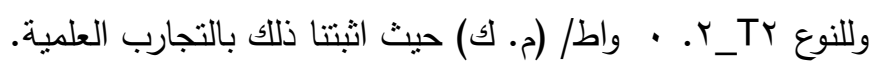

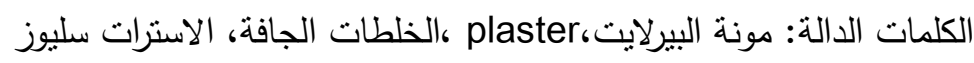

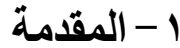

ان الزيادة الهائلة والمطردة في عدد سكان العالم وخاصة في الدول العربية يزيد من الحاجة الى البناء العمراني

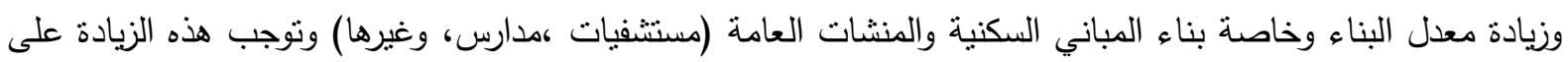
الحكومات والدول وضع خطط وبرامج للنطوير هذا القطاع الحيوي والمهم لكل دول العالم ،وقد لوحظ في العقود الثناث الماضية تطوراً هائلاً وكبيرا للبناء في الدول العربية وخاصة في دول الخليج العربي حيث اثتتت الدراسات التي اجراها قسم التخطيط الاقليمي والحضري في جامعة الملك فيصل على ازدياد الطلب على المساكن في السنوات القادمة في المملكة

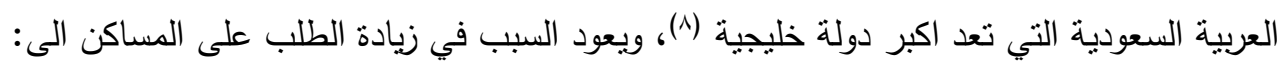
( ) النمو الاقتصادي وخاصة في دول الخليج العربي. r) زيادة عدد السكان. r) بالاستقرار الامني والسياسي. 
ولكن من طبيعة المجتمع العربي كان التركيز في البناء على المنازل السكنية والفيلات ,التي توفر الخصوصية،

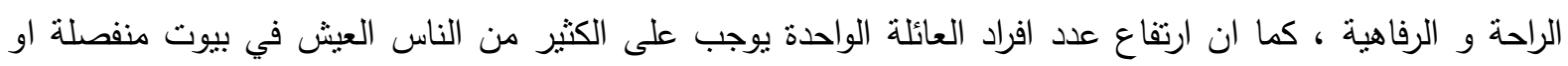

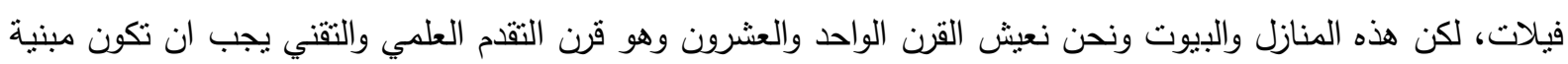

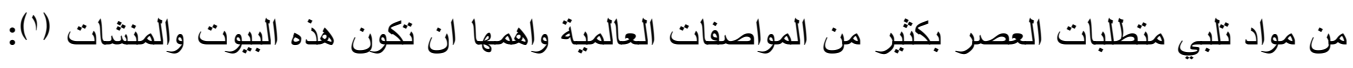
1- بات جدوى اقتصادية(قليلة التكلفة).

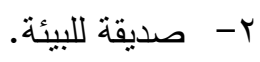
ب- موفرة للطاقة. ع- ذات تصميم مناخي. 0- ان تلبي الثروط والمواصفات الانشائية والمعمارية.

ومن هنا يوجب علينا كمتصيين وباحثيين في هذا المجال ان نبحث ونطور مواد بناء تلبي الشروط السابقة.

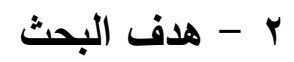

يهذف البحث الى بيان اهم ميزات الخلطات الجافة (خلطات البيرلايت) التي تستخدم في الوقت الحاضر بشكل كبير في تلييس المباني والمنشات، وتبيين اهم المواصفات والثروط التي يجب ان تلبيها هذه الخلطات، وكذلك المضافات

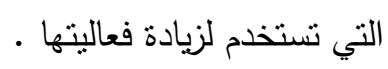

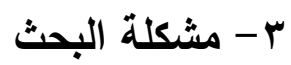
ان عدم توفر المواصفات القياسية (المعيارية) في الخلطات الجافة يعمل على الابتعاد عن استخدامها رغم اهميتها وايجابياتها العالية.

\section{ع - اهم المواصفات العالمية التي يجب ان تلبيها مواد البناء الحديثة}

في كل عام يزداد الطلب العالمي على الطاقة وايضا على طرق واساليب نوفيرها والاقتصاد في استخدمها, لضمان مستقبل الاجيال القادمة ،وهذا يوجب علينا كاخصائيين في مجال البناء ومواده ان نبحث ونطور مواد تكون موفرة للطاقة وصديقة للبيئة وذات جدوى اقتصادية, وقد لوحظ في الاعوام الماضية وخاصة قي الدول المتقدمة ازدياد الطلب

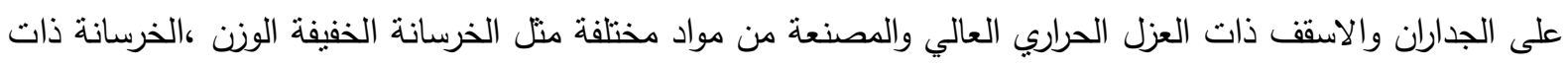
الهواء المحبوس ،الطابوق الاحمر وغيرها من المواد الحديثة التي تمتاز بانها: 1- (- خفيفة الوزن.

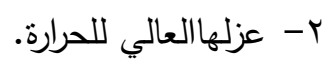
r- المسامية العالية. ع- مقامتها للانكماش (resistance to shrinkage). 0- مقاومتها للتنققات التي قد تظهر في مواد البناء المختلفة وغيرها. ومن هنا ان استخدام هذه للمواد يحتم علينا استخدام طبقة مونة التلييس (القصارة)ربحيث تكون هذهاء هذه الطبقة ذات

مواصفات عالية, وتلبي منطلبات المواصفات والمقاييس العالمية الحديثة. ولكن للاسف وللمفارقة انه ليس هناك نوافق واتصال جيد بين عملية انتاج مواد البناء من جهة, وبين المختصبين

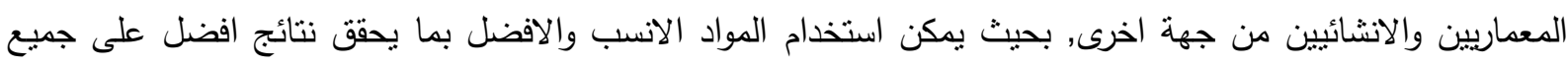

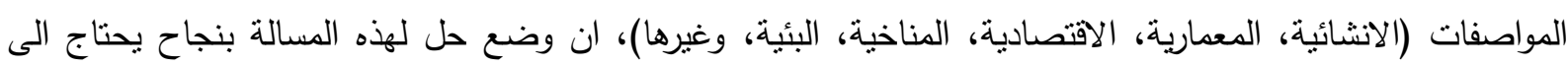
وضع قاعدة بيانات تقنية تلائم هذا النقدم والتطور العمراني الكبيروكنلك النطور الحاصل في عملية انتاج مواد البناء(؟). 


\section{ه- - اهم ميزات مونة البرلايت}

ان الاستخدام الكبير للمونة في عملية التلييس (plaster) تجعلنا نحث على استخدام وتطوبر المونة العازلة

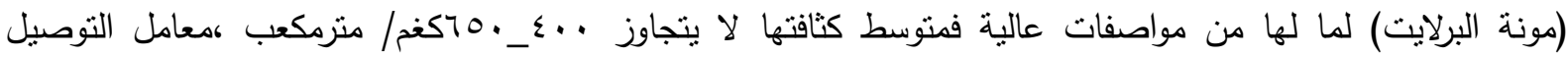

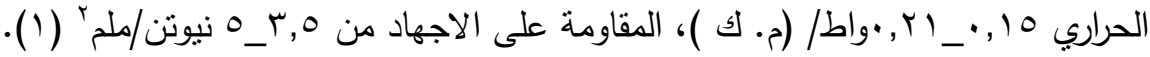
ان الانواع المختلفة من المونة الاسمنتية على اساس البيرلايت تمناز بقدرتها العالية على عزل الحرارة حيث تستخدم في تلييس السطوح الداخلية والخارجية للجدران والاسقف مع معامل توصيل حراري لايزيد r,،•عن فوط /م. درجة كلفن حسب المواصفات الاوربية للمونة الخلطات الجافة رقم (prEN9१ی-1).

تجعل هذه الخصصائص المونة اخف من المونة العادية وتقوم بعزل افضل للمباني فعلى سبيل المثال بـــ سم من التلييس بمو نة البيرلايت يعادل نصف بلوك (طابوق احمر),وكذلك التركيب الكيميائي للبيرلايت يجعله اكثر حماية للمباني والعناصر الانشائية من الحرائق وذلك ان عند ارتفاع درجة الحرارة تقوم طبقة مونة التليس من البرلايت باخراج

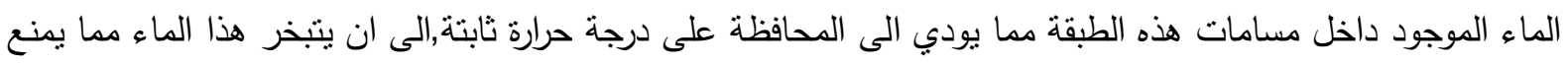

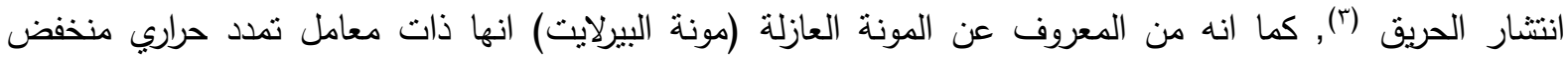
ممايساعد على عدم ظهور التشققات التي ثقوم بتسريب الحرارة، ومن خصائص مونة البرلايت انها مقاومة للتشوهات والكلال وكذللك مايعرف في مواد البناء بالزحف, وهذا بدوره يساعد المونة على اضعاف الاجهادات التي تتتج بين سطح طبقة التليس(الاساس) الداخلية وطبقة التليس الخارجية او مايعرف بطبقة البياض, بعكس مونة التليس العادية التي تتكون عادة من الرمل والاسمنت التي تتصدع وتتساقط بشكل مستمر ران احتواء البيرلايت على شعيرات مسامية يجعل المونة مانة

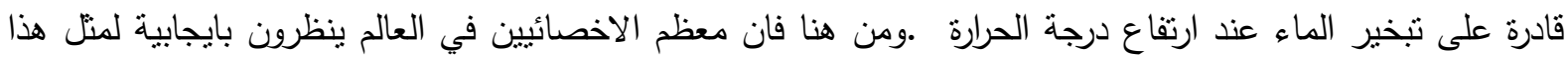
النوع من المونة وللمستقبل الواعد لها واستخدامها في تلييس المنشات و المباني السكنية وكذللك المنشات العامة (َ).

\section{4-الفرق بين مونة البيرلايت والمونة العادية.}

تتميز مونة البرلايت عن المونة العادية بانها سهلة في عملية التليس(عملية التشكيل على الاسطح)، تمتاز باللدونة، منخفضة الارتداد عن تعرضها للضربات الميكانيكية، ان المونة العادية عند وضعا على اسطح الخرسانة التي تحتوي على مسامات تقوم مباشرة باعطاء قطارات الماء التي بداخلها, ممايجعلها هشة عند جفافها،المونة العادية (الأمنت والرمل) لا تحتوي بشكل كافي على مسامات التي تسمح بتمرير القطرات الصغيرة من الماء (قطرات الندى) ,التي تعمل على ترطيب الجدران وبالتالي ترطيب وتبريد الجو عند ارتفاع درجة الحرارة ،كل هذا يعطي ويساعد الامكانية,

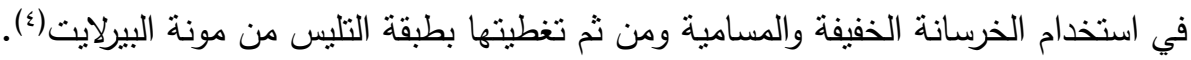
هذه المونة سهلة الاستخدام ويمكن عمل منها طبقة تليس من ه الى • ب ملم هذه الطبقة بطبيعة الحال يجب ان تحتوي على الماء بحيث يمكنها من التصلب بشكل جيد وكذلك يجب ان تكون خفيفة الوزن هذه الخصائص لايمكن الحصول الى باستخدام البرلايت والاضافات الكيمبائية (†). V

بناءاً واعتمادا على كثير من المراجع والمواصفات الروسية والالمانية والاروبية للخلطات, الجافة رقم قمنا بتجهيز الكثير من العينات للاختبار ,وذلك باستخدام البيرلايت مراعيين نسبة (EN 991) (DIN) 100, DINorT) 0 الماء ومعامل التهدل(slump test) , للخلطات المونة (مونة التليس),وقمنا باستخدام الاسمنت البوردتلاندي كمادة لاصقة

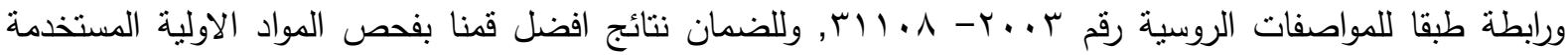


وهي الاسمنت, والبرلايت والمضافات الكيميائية, وتبين الجدوال التالية الفحصوات المخبرية وكذلك انواع المضافات المستخدمة ووظيفة كل نوع.

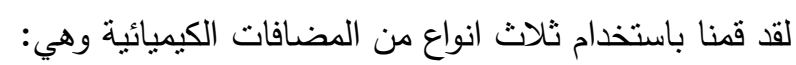
Moviliti puler التحكم في وقت جفاف المونة, كما يساعد هذا المضاف على تسهيل عملية تشكيل المونة على الاسطح المختلفة وتعتبر الميزة لهذا المضاف هو زيادة قدرة مونة البيرلايت على الالتصاق مع سطح الاساس بسبب (C-S-H ge)

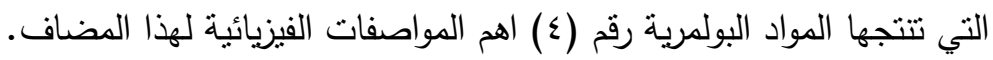

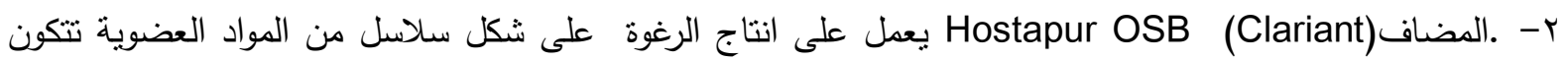
على السطح الخارجي للمونة تحميها من التشققات وكذلك الصقيع كما يعمل هذا المضاف على تقليل وزن المونة رقم (0) اهم المواصفات الفيزيائية لهذا المضاف. r- المضاف Tylovis SE V مضاف مثنن على اساس النشا يستخدم في مونة التلييس مع مساحيق معدنية

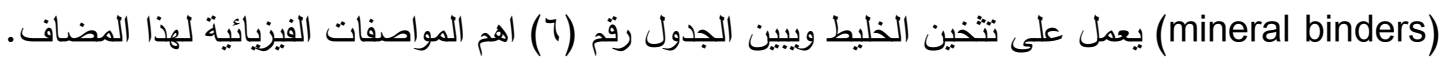
في عملية تجهيز العينات قمنا بتحديد العلاقة بين نسبة البيرلايت والاسمنت وكذلك نسبة الماء الى نسبة الاسمنت بما ينوافق وينطبق مع المواصفات الفنية والتقنية. ان نسبة الماء الى الاسمنت تم تحديدها بعد عمل مجموعة من التجارب على عينات مختلفة ونم تحديد بدقة النسبة الافضل لكل محتوى (الاسمنت, البيرلايت, المضافت الكيميائية، حيث من المعلوم ان الخطء في نسبة الماء بالزيادة او النقصان يسبب مشاكل كثيرة في عملية التليس وجودتها ،حيث ان زيادة الماء في الخليط يودي الى ظهور التشققات وانخفاض المقاومة على اجهاد الضغط، حيث يمكن زيادة ميوعة الخلط

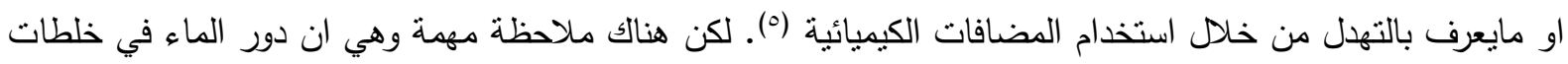
المواد العازلة ليس فقط للخلط العجينة او المونة انما للحصول على اكبر نسبة من المسامية التي تقوم بنتبريد وتلطيف الجو عند ارتفاع درجات الحرارة من خلال تبخر جزيئات الماء ('). من خلال التجارب التي قمنا بها حصلنا على الرسم البياني الموضح في شكل رقم (ع) الذي يوضح علاقة الاجهاد على الضغظ والكثافة الى نسبة الاسمنت والبرلايت. حيث من

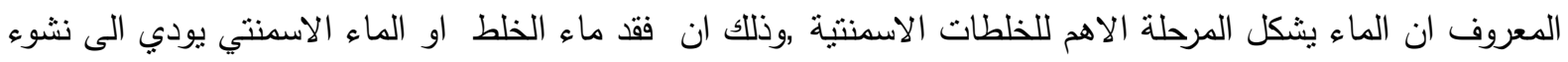

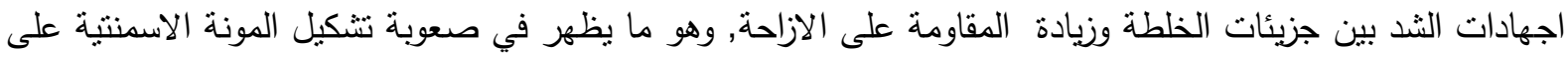
الجداران, او غيرها من العناصر الانشائية، وللحصول على مونة ذات جودة ومواصفات عالية قمنا باضافة المواد

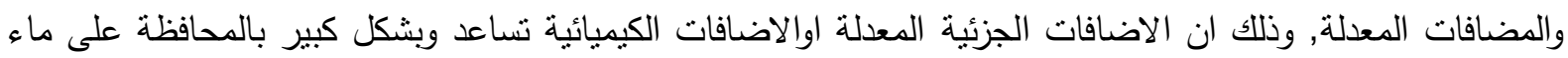
الخلطة الاسمنتية, بحيث تكون سهلة عند تشكيلها على الاسطح المختلفة او يمكن القول بصيغة اخرى ان اضافة مادة الاسترات سليوز(cellulose esters) على سبيل المثال الى الخليط يساعده على زيادة زمن الثكك وعدم جفاف المونة

بشكل سريع ممايضمن الحصول على سطح من, التليس لايحتوى على نشققات او تصدعات اومايعرف بالانكماش( (؛). هذا المسحوق (cellulose esters) يعطي مسامات العجينة الاسمنتية طبقة مطاطية تساعد على زيادة قوة الترابط والتماسك بين جزيئات البيرليت والاسمنت،ويزيد من المقاومة على اجهادات الضغط والثد وكذلك عزم الانحناء و يقلل من عملية امتصصاص الماء, وكذلك قمنا في تجربتتا باستخدام مسحوق Hostapur OSB المنتج للمسامات، ومن هنا قمنا ومن خلال التجربة معرفة تاثير بعض الاضافات على الخصصائص الميكانيكية والفيزيائية على مونة البيرلايت، وقمنا من خلال النتائج التي حصلنا عليها بتحديد النسب المنلى للكل مضاف على ملى مونة البيرلايت وعلى خصائصسه الفيزوميكانيكية وقد اعتمدنا الطرق الرياضية في التجارب(؟). حيث تعتمد هذه الطرق على تحديد واختيار مكونات الخلطات 
من خلال المعادلات الرياضية, ومن ثم وضع علاقة رياضية بين خصائص ومواصفات المواد من جهة, وبين كمية ونسب المواد المستخدمة من جهة اخرى ،بحيث تحدد وبشكل دقيق مواصفات وخصائص الاضافت والمواد وناثير نسبة كل مادة اومضاف. من خلال المعايير والمعطيات كان اختبار العينات اعتمادا على الخصائص التالية: 1- 1 الكثافة ب ب الاجهاد على الضغط r- ب نسبة الماء في الخلط

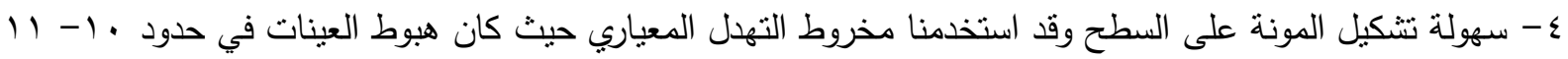
سم مع تركيز مختلف للمضافات الملدنة والمخفضة للماء.وقد حصلنا من خلال التجارب والاختبارات على معامل رياضي يوضح تغير الخصائص الفيزوميكانيكية للمونة البرليت ،وكذللك استطعنا الحصول على علاقة توضح نسبة مكونات الخلطات الجافة (خلطات البرلايت) حيث تعتبر العينات الافضل والامتل تلك العينات التي تحتاج اضافات اقل حيث من المعروف انه كلما قلت نسبة المضافات انخفضت التكلفة بحيث لا توثر بشكل سلبي على الخصائص الفيزوميكانيكية

للخليط (r) (ب).

يمكن تصوير تاثير المضافات الجزئية المعدلة منل مسحوق الاسترات سليوز (esters cellulose ) والمساحيق

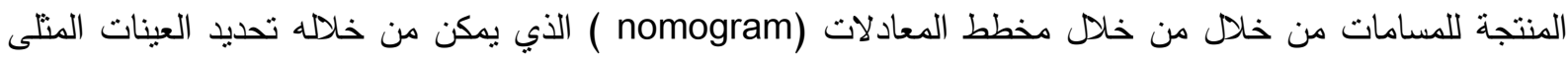
وكذللك العوامل والموثرات في كل عينه، ويمكن من خلال مخطط المعادلات التحكم بمواصفات العينات ,وكذلك نسبة

المكونات بالزيادة او النقصان وذللك للحصول على الخلطة المطلوبة كماهوموضح في الثكل (ه).

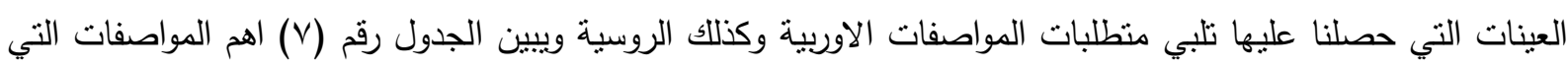
حصلنا عليها والمواصفات الي يحددها الكود الاوربي للمونة البيرليت للاستخدامات التلييس ،العينات التي قمنا بالتوصل اليها والتي تلبي منطلبات المواصفات العالمية يمكن اعتمادها للاى الثركات ومصانع مواد البناء وكذلك يمكن الاعتماد عليها في البحث العمي مسنقبلا وتطويرها.

\section{مناقشة النتائج ومقارنتها مع نتائج اخرى.}

في نهاية البحوث والاختبارات حصلنا على مونة للتبييض من الاسمنت ورمل البيرلايت والتي تمتاز بالخصصائص التالية:

$$
\text { ا. الالتصاق الجيد مع سطح الاساس. }
$$

r. بذات قابلية منخفضة للامنصاص الماء.

r.قدرتها على الجفاف بعد تعرضها لاي نوع من الرطوبة.

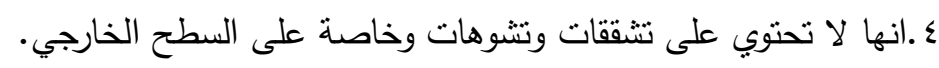

ه.ذات مسامية عالية.

7 .ذات معامل توصيل حراري منخفض.

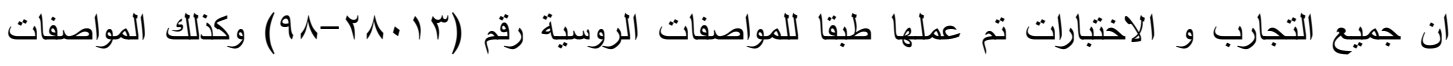

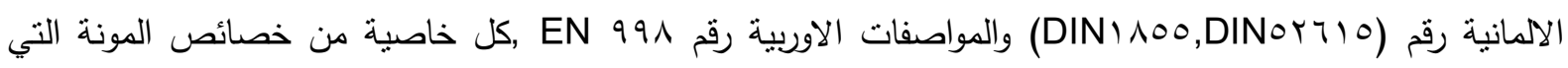

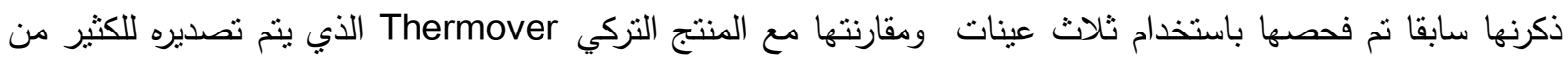

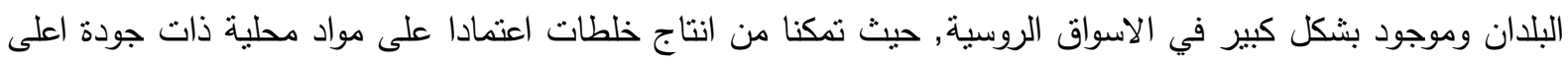


من الخلطات التركية كما هو موضح في الجدول رقم (V) كما يعتبر استخدام مواد خام محلي ذات جدوى اقتصادية وله تاثير كبير في المحافظة على البيئة حيث من ,المعلوم ان الخلطات الجافة باستخدام رمل البيرلايت من المواد الصديقة للبيئة.

قمنا بقياس وزن الخلطات المنتجة حيث كان وزنها من ب- ؛ ا قل من المونة الاعتيادية (الاسمنت+الرمل) التي

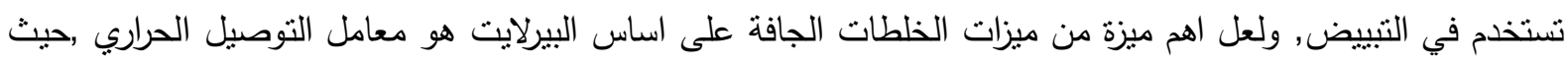

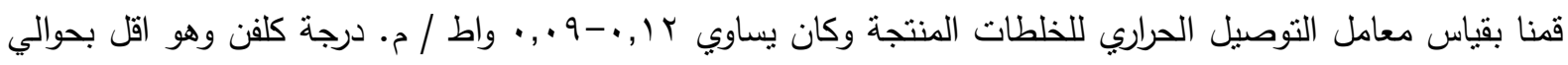
• ا مرات من معامل التوصيل الحراري للمونة الاعتيادية حيث كان معامل التوصيل الحراري للمونة الاعتيادية -9.9. .,.

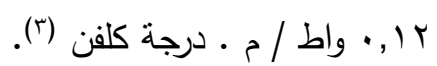

تم خلال التجارب فحص العينات على اجهادات الضغط والذي يعتبر من الخصائص المهمة للمونة حيث كانت

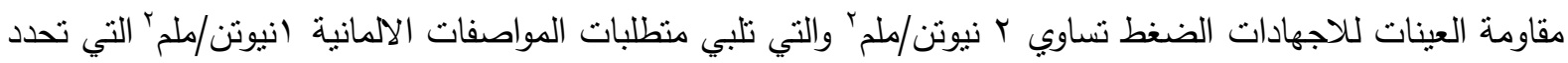

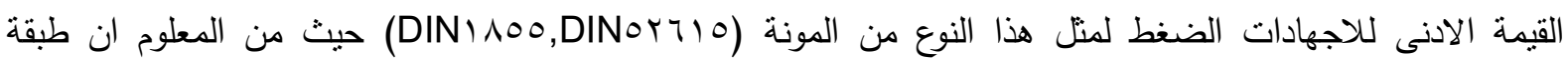

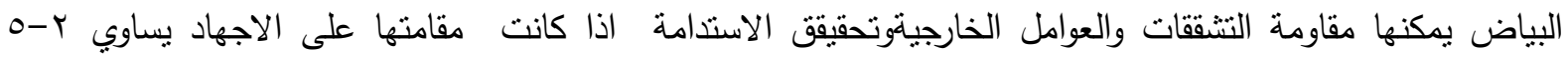

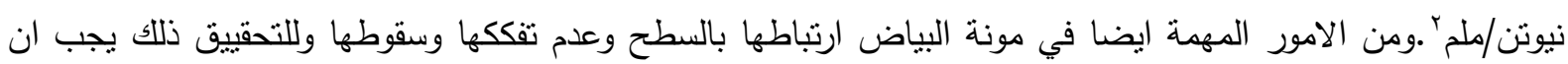

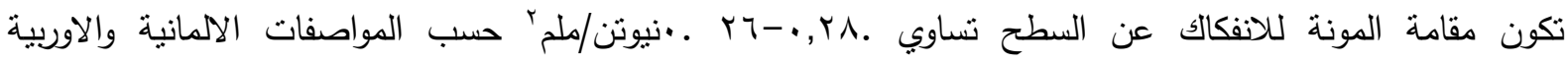
DIN و وهذا مانت تحقييق في الخلطات المنتجة.

\section{النتائج والتوصيات.}

من خلال نتائج التجارب العملية التي حصلنا على خلطات جافة باستخدام البيرليت ذات مواصفات عالمية وتلبي بالاساس متطلبات المواصفات الاوربية حيث اثتتنا ذلك بالتجارب العملية وكذلك النظرية حيث يمكن استخدام هذه الخلطات في عملية التلييس حيث كانت الخلطات بالاساس من البيرليت مع اضافة المضافت الكيميائية والمضافات الجزئية المعلة وكذلك المضافات البولمرية ،التي تساعد على زيادة قوام الخلطات وتحسن من ادائها. حيث تستخدم هذه الخلطات بشكل واسع في عملية البناء وخاصة التبييض (القصارة).

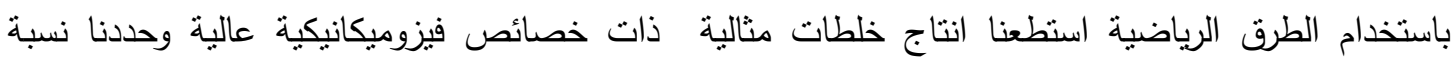
المضافات في كل خليط. ومن هنا نوصي باستخدام المضافت منل مسحوق (Hostapur OSB) (Mowilith pulver) الاسترات سليوز (cellulose esters) في الخلطات الجافة التي تساعد وبشكل كبير في تحسين الخصائص

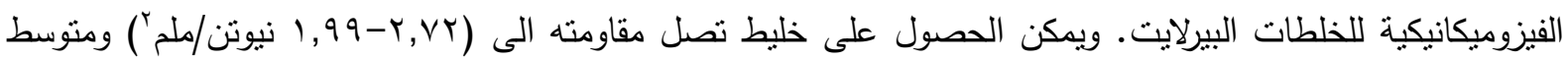

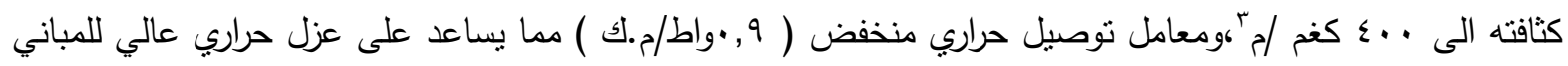
مما يساعد بشكل كبير على توفير الطاقة ويحافظ على البيئة ويحقق الاستدامة للمباني.

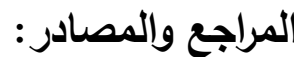

1. Shirina N.V., Zagorodnyuk L.H. Effectual constructional mixtures for insulation works: monograph/ N.V. Shirina, L.H. Zagorodnyuk- Belgorod: est. BSTU $\uparrow \cdot 1 \cdot-1 \wedge \varepsilon p$. 
r. Kazarnovskiy Z.I. Insulation of fence assemblies, sanitation and hydro isolation using dry mixtures. Z.I. Kazarnovskiy, L.M. Omel'chenko, G.N. Savilov //Construction materials/ $1999,-\# r^{-}-p . r \varepsilon-r_{0}$.

r. Nazcievskiy S.U. on modern concrete, dry constructional mixtures and nonflammable

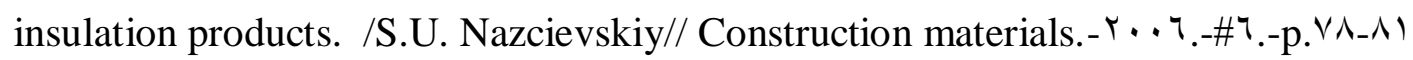

£. Udodov S.A. Features of properties on dry mixtures using porous aggregates / S.A.

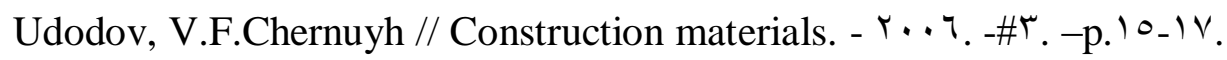

•. Runova R.F. Features of using mineral astringents on dry constructional mixtures /R.F. Runova, U.L. Nosovskoi //Modern technology of dry mixtures in construction: article $\mathrm{r}^{\mathrm{nd}}$ International science-technical conference. $-\mathrm{Spb}, \uparrow \ldots$.

ๆ. Zagorodnuyk L.H. Constructional mixtures. The Past and the Future: monograph /L.H. Zagorodnuyk, N.V.Shiriga. -Belgorod: est. BSTU, ץ. . . - r 19 p.

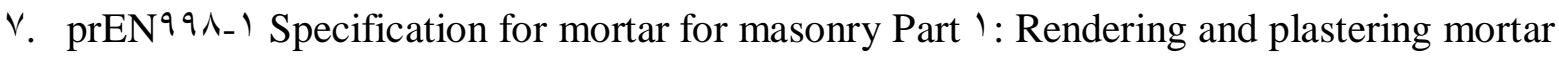
^. تقدير اعداد سكان ومساحة ونوع المساكن في المملكة العربية السعودية للعشرين سنة القادمة, الدكتور فه بن نويصر الحريقي, الدكثور عدنان بن عبدالله الثيحة, الدكتور جمال الدين بن يوسف سلاغور •

الجدول (1): التركيب الكيمائي للاسمنت المستخدم.

\begin{tabular}{|c|c|c|c|c|c|c|c|c|}
\hline \multirow{2}{*}{ الاسمنت } & \multicolumn{8}{|c|}{ التركيب الكيميائي, \%.الكتلة } \\
\hline & $\mathrm{SiO}_{r}$ & $\mathrm{Al}_{r} \mathrm{O}_{r}$ & $\mathrm{Fe}_{r} \mathrm{O}_{r}$ & $\mathrm{CaO}$ & $\mathrm{MgO}$ & $\mathrm{SO}_{r}$ & $\mathrm{R}_{T} \mathrm{O}$ & ППП \\
\hline 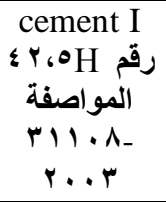 & $r \cdot, \wedge_{ \pm}$ & $\varepsilon_{6} \wedge \mu_{ \pm \cdot \bullet 0}$ & $\varepsilon_{6} \cdot V_{ \pm} \cdot 60$ & $\begin{array}{c}T \varepsilon_{6} T \Lambda_{ \pm} \\
r\end{array}$ & - & $r_{6} O V_{ \pm} \cdot 6.0$ & $\cdot 6 r \cdot \pm \cdot 6 \cdot 0$ & $16 \cdots \pm \cdot 6 \cdot 0$ \\
\hline
\end{tabular}

الجدول (ץ): المو اصفات الفنية والتقنية للاسمنت المستخدم.

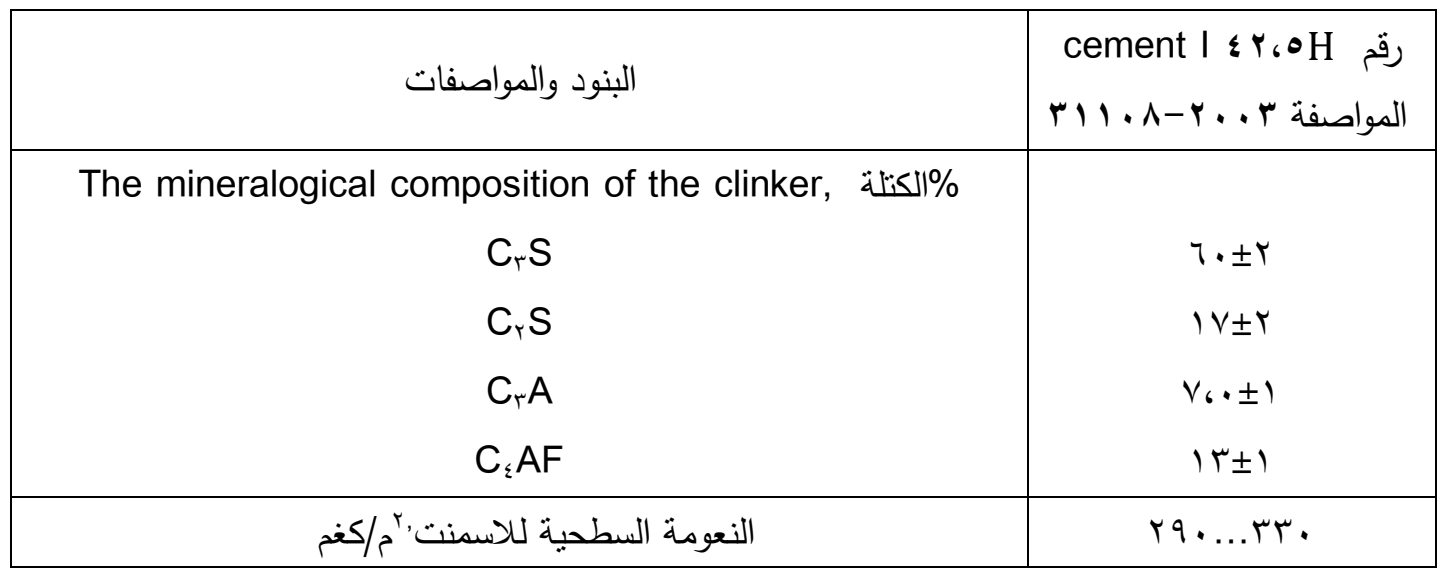


استخدام مونة البيرلايت في تلييس المنشات والمباني السكنية

\begin{tabular}{|c|c|}
\hline الكثافة الطبيعية للعجينة الاسمنتية \% & $r \leq \pm \cdot .0$ \\
\hline زمن الثكك للعجينة الاسمنتية, دقيقة & \\
\hline بداية زمن الثك & $1 \ldots-1 \leq$ \\
\hline نهاية زمن الثك & $1 \wedge \cdot-r \ldots$ \\
\hline الاجهاد على الضغط ^^ يوم, ميغاباسكال & $0 Y_{6} \cdot \pm 1,0$ \\
\hline
\end{tabular}

الجدول (ب): اهم خصائص وميزات رمل البير لايت المستخدم.

\begin{tabular}{|c|c|}
\hline اهم الخصصائص والمواصفات & القيمة والنوع \\
\hline قيمة الكثافة الظاهرية & $1 \ldots$ \\
\hline التدريج الحبيبي حسب المجموعة & منوسط \\
\hline رم/ بكغم: الكثافة الظاهرية للندرج الحبيبي & \\
\hline 1, YO-Y.0 mm & $7 \Lambda_{6} \varepsilon$ \\
\hline $.67 r-1,60 \mathrm{~mm}$ & $11 \leq 69$ \\
\hline .610-. & $1 \varepsilon$. \\
\hline $.617(.6) \varepsilon)-.6410 \mathrm{~mm}$ & $1 \leq r_{6} \wedge$ \\
\hline.-.6$) 7(.6) \leqslant) \mathrm{mm}$ & $10 r 61$ \\
\hline 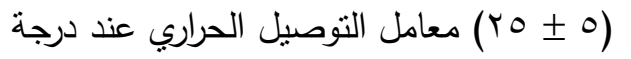 & .6 .04 \\
\hline \%الرطوبة \% & r \\
\hline
\end{tabular}

الجدول (؛ ): اهم المواصفات الفيزيائية للمضاف Mowilith Pulver

\begin{tabular}{|c|c|c|c|c|c|}
\hline النوع & كمية المو اد & 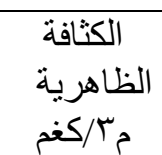 & الفحم المتطاير من رماد , & $\begin{array}{c}\text { Transition } \\
\text { temperature } \mathrm{Tg}, \\
{ }^{\circ} \mathrm{C}\end{array}$ & $\begin{array}{c}\text { Minimum Formation } \\
\text { Temperature MFT, } \\
{ }^{\circ} \mathrm{C}\end{array}$ \\
\hline $\begin{array}{l}\mathrm{LDM} \\
r \cdot \wedge \cdot P\end{array}$ & $99_{ \pm 1}$ & $\leqslant 0 . \pm 1 \ldots$ & $960 \pm 1, r_{0}$ & ок. - ₹ & ок. · \\
\hline
\end{tabular}

الجدول (•): اهم المواصفات الفيزيائية للمضاف Hostapur OSB

\begin{tabular}{|c|c|}
\hline المعطيات & الخصائص \\
\hline الثكل الخارجي & ناعم ويميل لونه الى الاصفر \\
\hline Charge & anionic \\
\hline الرطوبة\% & $r$ \\
\hline المحتوى من كبريتات الصوديوم\% , & 0,0 \\
\hline المحتوى من كربونات البوتاسيوم\% , & $\varepsilon$ \\
\hline الكثافة الظاهرية مب/كغ & $r \ldots$ \\
\hline
\end{tabular}


استخدام مونة البيرلايت في تلييس المنشات والمباني السكنية

Tylovis SE V الجدول (†): اهم الخصائص الفيزيائية للمضاف

\begin{tabular}{|c|c|}
\hline ال المعطيات & الخصائص \\
\hline النشكل الخارجي & مسحوق ناعم \\
\hline الذوبانية & يذوب في الماء \\
\hline الرطوبة \% & 0 \\
\hline مץ/ الكثافة الظاهرية كغم & 7. \\
\hline التدرج الحبيبي\% & \\
\hline$<\cdot, 1 \wedge \mathrm{mm}$ & 99 \\
\hline$<\cdot 6) \cdot \mathrm{mm}$ & 9. \\
\hline The reaction of $1 \%$ solution & Neutral to slightly alkaline \\
\hline
\end{tabular}

الجدول رقم (V): اهم الخصائص والمواصفات التي حصلنا عليها ومنطلبات المواصفات العامة.

\begin{tabular}{|c|c|c|c|c|}
\hline $\begin{array}{l}\text { المنتج التركي } \\
\text { Thermover }\end{array}$ & r المنتج رقم & رقم المنتج & متطلبات & الخصائص والموشرات \\
\hline$\varepsilon \vee$. & $\varepsilon q$. & $\varepsilon \varepsilon$ & 0. & متوسط كثافة مونة التلبس من البرلايت (كغخ/مّ ) \\
\hline AV & $91, \wedge$ & qr, & 9 . & خاصية الاحتفاظ بالماء \% \\
\hline$\cdot, 1$ & $\cdot, \mathrm{\wedge}$ & $\cdot, r_{\top}$ & $\cdot, r$ & قوة الالتصاق مع سطح الاساس(البلوك) ميغاباسكال \\
\hline$\vee, r$ & $\varepsilon, \wedge r$ & $\varepsilon, \varepsilon \varepsilon$ & - & امتصاص الماء عن طريق الشعيرات(كغم/م' ) \\
\hline$\cdot, \cdot v$ & $\cdot, 11$ & $\cdot, \cdot 7$ & $\cdot, \cdot r$ & معامل النفاذية مغ /م •ج •باسكال \\
\hline- & ل ل الا يوجد & 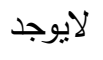 & ل ل الا يوجد & 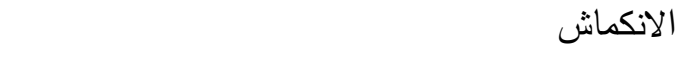 \\
\hline r & r, r & r, r & $1, \cdot$ & الاجهاد على الضغط ميغابسكال \\
\hline$\cdot, 1$ & $\cdot, 14$ & $\cdot, .9$ & $\cdot, r$ & معامل التوصيل الحراري واط / م. درجة كلفن \\
\hline 0 . & vo & vo & ○. & مقاومة الصقيع ، دورات \\
\hline
\end{tabular}




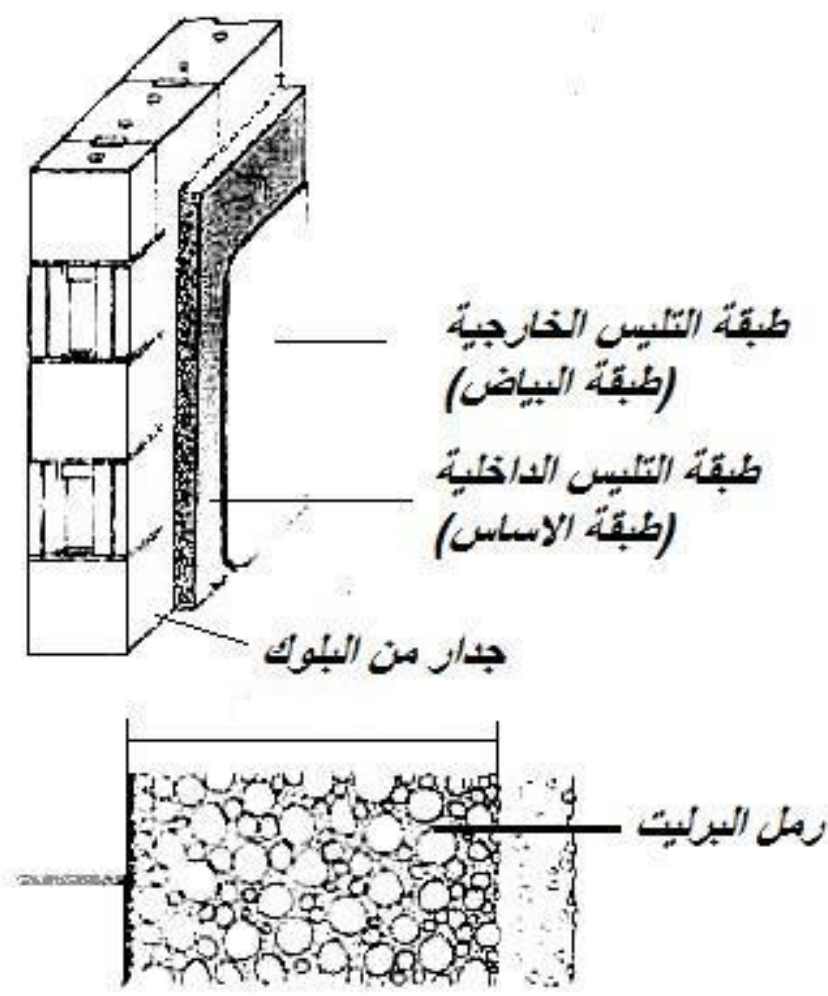

الثكل رقم (1): التليس (القصارة) العازلة, صورة نوضيحية لعملية التلبيس من مونة البيرليت.

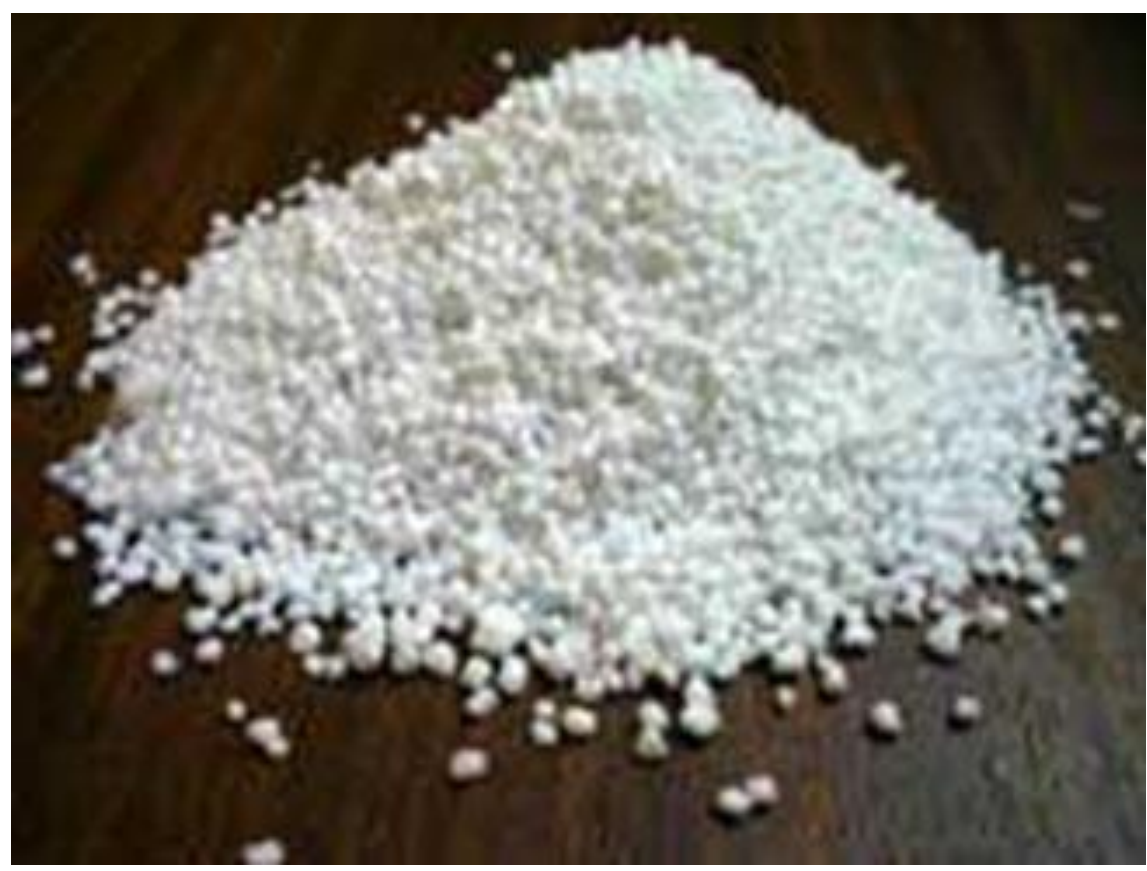

الثكل رقم (ץ): صورة توضيحية للبيرلايت الطبيعي من الصخور البركانية. 


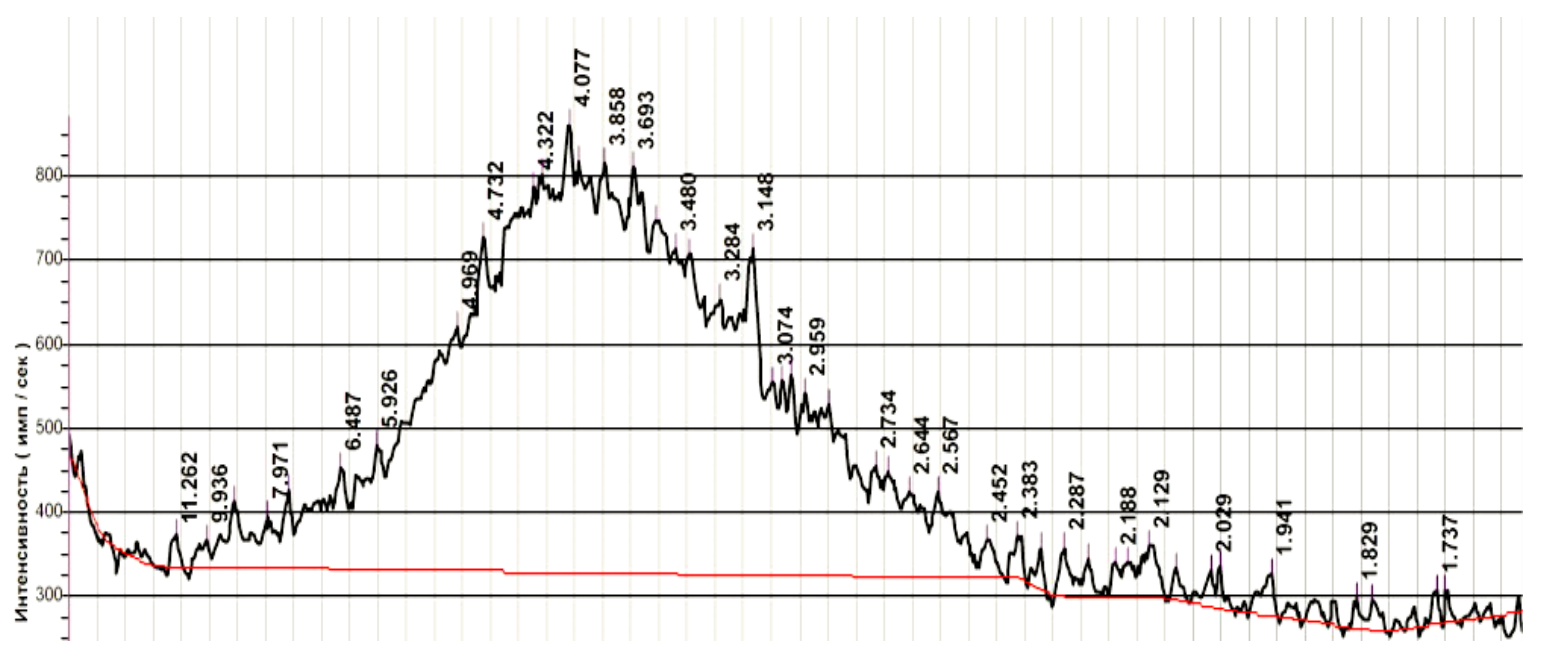

الثكل (ץ) (roentgenogram) للرمل البيرلايت المستخدم. صورة اشثعاعية

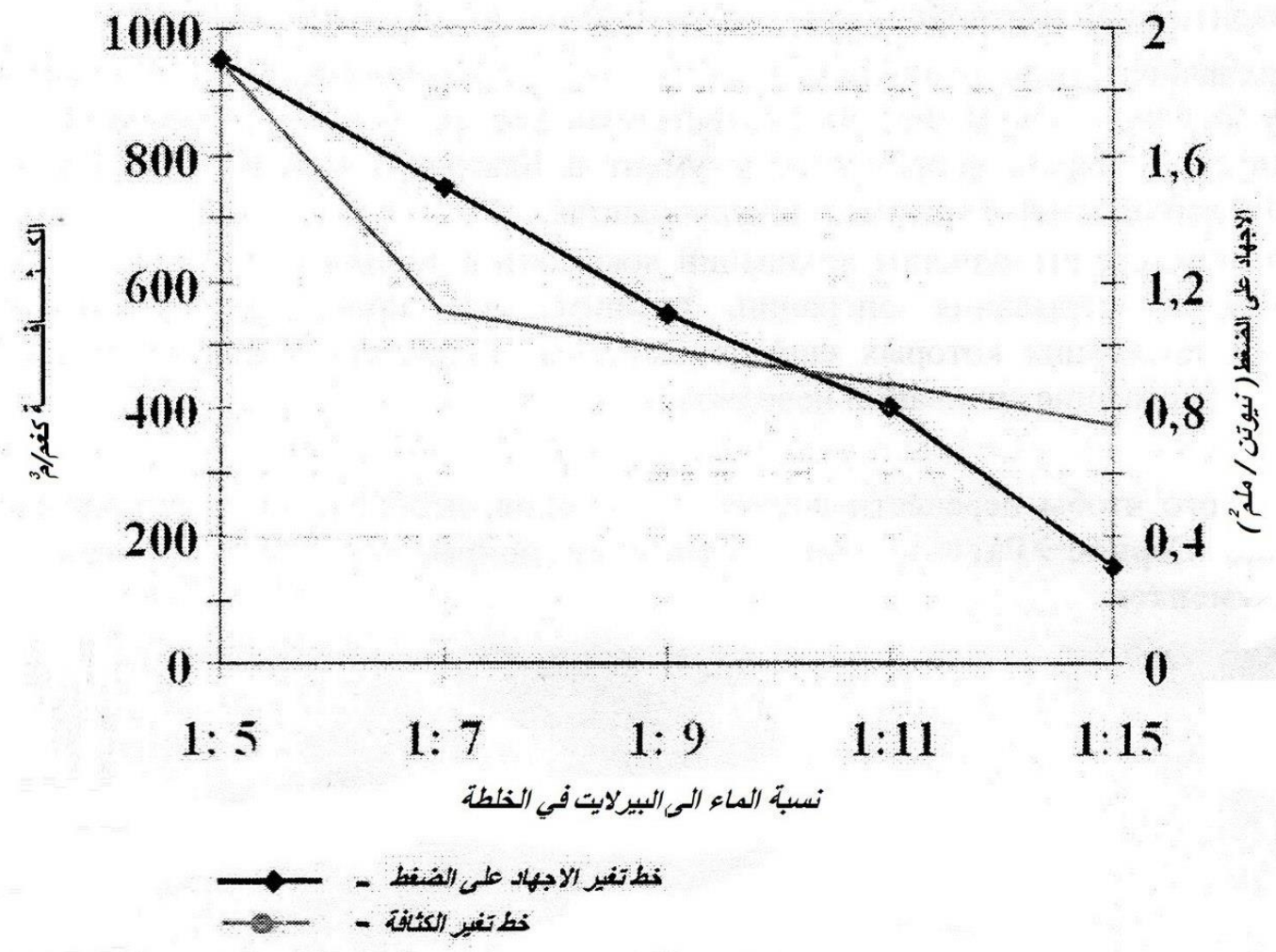

الثكل (ء): العلاقة بين الاجهاد على الضغظ والكثافة الى نسبة الماء والبرلايت. 

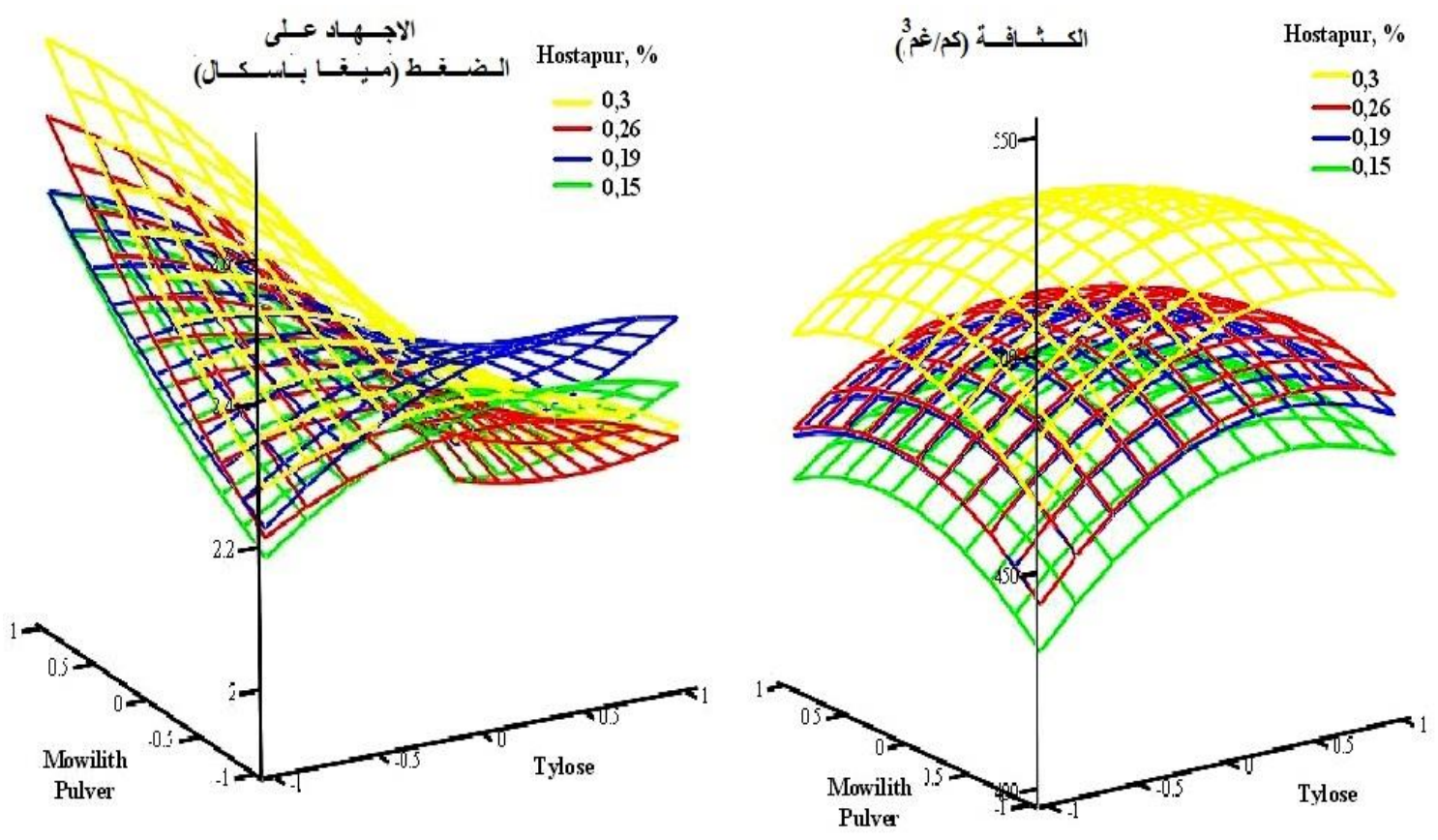

الثكل رقم (•): توضيح نائير المضافات المعدلة والمضافات على خلاطات البيرلايت. 


\title{
USING A SOLUTION BASED ON PERLITE SAND PLASTER DECORATION OF BUILDINGS AND STRUCTURES
}

\author{
Professor Zagorodnjuk L. H., Professor Lesovik V. S., Dr. Mahmoud Shakarna \\ Belgorod State Technological University / Russia
}

\begin{abstract}
The nature of Arab society to focus on building on the houses and villas that offer privacy and comfort and luxury, and the high number of family members per requires a lot of people living in the homes of separate or villas. These houses should be built from materials which have the international standards in this area. One of the most important of these specifications are dry mixes.

The research aims to indicate the most important features dry mixes (perlite mixtures) which are used at present significantly whitening buildings and structures, and to indicate the most important specifications and requirements that must be met by these mixtures, as well as additives that are used to increase their effectiveness.

There were reached by the results of scientific experiments that we got a dry mixtures using world-class pearlite and basically meet the requirements of European specifications that determine heat recommendation of the type $\mathrm{T}^{\prime}{ }_{-}{ }^{\prime} \cdot \cdot \mathrm{W} /(\mathrm{m} . \mathrm{K})$, and the type of $\mathrm{T}^{r}{ }^{r} \cdot{ } \cdot \mathrm{W} /$ (m. K) where we proved scientific experiments.
\end{abstract}

